\title{
O pícaro beato e o beato pícaro
}

\author{
Paulo de Tarso Cabrini Júnior \\ FAFIL - Carlos Queiroz/SP
}

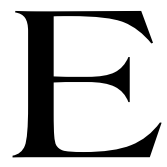

ste artigo versa sobre a influência da novela picaresca sobre a prosa portuguesa dos séculos XVI, XVII e XVIII, e sobre o tratamento singular dado pela literatura portuguesa no que se refere ao realismo, inovação literária trazida pela picaresca, e desenvolvida, posteriormente, pelo romance moderno.

Até o século XIX, as tentativas de se fazer, em Portugal, uma novela realista foram tentativas frustradas. Nenhum outro país europeu, que se saiba, sofreu tanto com o controle ideológico como aconteceu com Portugal.

O "tratamento singular", a que nos referimos, diz respeito a uma necessidade ímpar de se apegar à tradição da prosa medieval; por conta desse apego, temos uma série de narrativas em prosa marcadas por tentativas de realismo que nos parecem, para usar uma metáfora altamente explicativa, sufocadas. E os melhores objetos de estudo desse realismo frustrado da literatura portuguesa são precisamente as novelas que se quiseram picarescas, e uma outra espécie de literatura que, embora não possa ser chamada de picaresca, manifesta o mesmo espírito cético propagado pelo gênero espanhol, que marcaria indelevelmente a literatura mundial.

A novela picaresca espanhola, surgida no século XVI, acabou por trazer à literatura dois elementos revolucionários e indissociáveis. Examinemos ambos, antes de partirmos para o nosso objeto.

Os procedimentos "anti-literários" da picaresca espanhola, contrários, e ao mesmo tempo irmãos bastardos, daqueles utilizados pela literatura erudita e cavaleiresca, apontavam inevitavelmente para a tematização da realidade sensível, do mundo e do homem tal como são, invertendo o modelo literário cavaleiresco, de tematização de uma supra-realidade idealizada num espaço abstrato, cujo tempo é marcado pelas aventuras, ou pela mudança de cenas.

Talvez essa inovação não tivesse sido possível sem a contribuição do ponto de vista autobiográfico, que reforça a "veracidade" da história. Agindo assim, a picaresca não só subvertia, pela sátira, a literatura erudita, 
mas dava à realidade o status de objeto literário. É nesse sentido que a novela picaresca surge como forma literária popular, que não exclui o universo de expectativas do leitor comum.

Ao lado desse aspecto formal, o anti-herói, ao dar-nos a sua visão da realidade sensível, acaba nos trazendo aquele elemento pragmático que é fruto direto do realismo. A problematização do mundo e do homem são elementos denunciadores do abismo entre essência e aparência, um tema extremamente caro à picaresca.

Contudo, a rigor, podemos dizer que só houve uma novela picaresca portuguesa. A existência de uma obra apenas não quer dizer, porém, que a picaresca espanhola deixou de influenciar um país limítrofe e historicamente semelhante à Espanha. Veremos, todavia, que essa influência é bastante superficial, e que a importância das obras por ela influenciadas se deve, nos dias de hoje, se não à qualidade literária, pelo menos ao documento de uma tradição brutal.

Num inteligente livro sobre o assunto, chamado Do pícaro na literatura portuguesa, João Palma-Ferreira apoia-se no estudo de Ulla M. Trullemans, Huellas de la picaresca en Portugal, para citar três obras que podem ser chamadas picarescas, embora seus apontamentos sejam passíveis de discussão, como se verá adiante.

A primeira dessa novelas é a Tercera parte del Guzmán de Alfarache, do Marquês de Montebelo (1529-1622), publicada somente em 1927. Escrita em castelhano, e na Espanha, conta a história do mesmo Guzmán que Mateo Alemán deixara na galé, em fase de arrependimento, e que é solto por ordem do rei, mediante a quantia de trezentos escudos de ouro, pagos ao capitão do barco. A partir daí, tem início uma nova série de aventuras, situadas, principalmente, em terras portuguesas, até o final, pouco picaresco, em que Guzmán se torna eremita.

Lida como novela picaresca, a Tercera parte é frustrante. Apesar da autobiografia, das malfeitorias e do pessimismo, o pícaro tende a realizar obras de reabilitação, e seu moralismo já não tem aquele caráter humano que marcaram o Guzmán, mas é uma clara confirmação do moralismo dogmático tão caro à tradição portuguesa das novelas de proveito e exemplo, beatas e clericais. O protagonista é colocado numa posição de espectador, e mais faz em ouvir as histórias picarescas de seus companheiros do que em agir como tal.

O segundo livro arrolado por Palma-Ferreira é El siglo pitagórico y vida de D. Gregório Gadanha, de Antonio Henriques Gomes, editado em 
Rouen, em 1644. O livro procura satirizar a tendência esotérica disseminada no século XVII, particularmente no que se refere à filosofia de Pitágoras, tornada popular em seus pretensos aspectos metafísicos. Henriques Gomes centra seu livro no tema da metempsicose (ou transmigração), que se inscreve no âmbito daquele salvacionismo e arrependimento que timbraram o século XVII. Passado na Espanha, o enredo conta a vida do protagonista, D. Gregório Gadanha, que sofre quatorze transmigrações, sendo na pele de um ambicioso, de uma dama, de um miserável, de um doutor, até a última transmigração, na figura de um virtuoso.

Uma série de procedimentos acabam por tornar o livro mais uma preocupação moralizante do que uma novela picaresca. A linguagem, pouco agressiva e espontânea, resvala na retórica conceptista de elegância barroca. O livro se torna, assim, mais uma novela que adota procedimentos picarescos dirigidos à reforma moral do personagem.

As Novelas exemplares, de Gaspar Pires Rebelo, foram originariamente editadas em Lisboa em 1650, e ganharam duas reedições posteriores. Neste volume está a novela portuguesa que é mais fiel ao espírito picaresco, O desgraçado amante Peralvilho, inspirado diretamente pelo Lazarillo de Tormes. A ação da novela se passa quase inteiramente em território espanhol, e conta as desgraças de Peralvilho, quase todas advindas de seu sentimentalismo acentuado, até que, experimentado pelos tormentos, se afasta das tentações e dos "trabalhos" provindos da paixão sensual. Dentre as outras novelas reunidas no mesmo volume, $O$ desgraçado amante Peralvilho se destaca por sua linguagem mais simples, clara e vivaz, ao contrário da prosa artificiosa, conceitual e aguda de outras, como Os gêmeos de Sevilha.

Palma-Ferreira, todavia, acentua que, malgrado esse feliz exemplo, a picaresca em Portugal estava condenada a apenas uma novela, uma vez que o espírito picaresco "nunca correspondeu a uma faceta característica da mentalidade portuguesa". E diz, não sem uma ponta de desalento, que mesmo o autor de O desgraçado amante Peralvilho procura refugiar seu pícaro no mundo castelhano, "onde essas loucuras eram mais consentâneas com o pitoresco" lingüistico, folclórico e geográfico. ${ }^{1}$

No mesmo trecho, Palma-Ferreira fala de falta de talento e imaginação nos escritores portugueses da época. De subalternização, provincialismo,

${ }^{1}$ PALMA-FERREIRA, 1981, p. 87- 90. 
saudosismo de glórias passadas, messianismo confuso, lirismo choroso, e outros epítetos que vinculam a literatura portuguesa a uma mentalidade mais apegada ao fantasioso e ao lírico, do que a literatura espanhola, mais pragmática e vivaz. Diz, ainda, que o português "não aceita, numa cultura modelada pelos heróis clássicos, o anti-herói e, quando ele surge, está associado, afinal, ao trajecto do aventureirismo exótico e à literatura dos roteiros".

Quero crer que o Autor apenas analisa os fatos, sem se deter nas causas. Não sem verdade, aponta características manifestas na produção literária portuguesa, mas por certo se esquece de um motivo capital que pode muito bem ser a origem de todos os outros que aponta. Impossível para o nosso senso acreditar que a inexistência, não somente de textos picarescos, mas de uma representativa literatura em prosa, seja devida à falta de talento. Difícil, também, é crer num pendor medieval generalizado, que simplesmente exclua o interesse pela produção de outros gêneros em prosa. Penso que a questão tenha sido mais externa do que interna aos escritores da época.

Até o momento, fica evidente que houve uma adoção parcial dos procedimentos da picaresca espanhola por parte de alguns autores portugueses; e que tal parcialidade inevitavelmente desequilibra o efeito da sátira, e inverte a função problematizadora do realismo. Não é difícil, portanto, arrolar as obras supracitadas naquele modelo ficcional que, em território português, esteve em voga até finais do século XVIII. Tal modelo literário pode ser representado pelas Aventuras de Diófanes, de Teresa Margarida da Silva e Orta (1752 e 1777), que seguem a tradição idealizante do romance grego, propagando o bom exemplo de caráter e de comportamento. Entre este livro e, por exemplo, a Tercera parte del Guzmán de Alfarache, há diferenças formais, de marcação do tempo, de construção do espaço e dos personagens, mas a intenção edificante parece surgir, entre as duas obras, como uma marca portuguesa inevitável. Parecia impossível escrever-se uma novela de pícaros, transcorrida em Portugal, sob a ótica cética, satírica e vivaz com a qual foram escritos o Lazarillo ou o Guzmán.

A história da literatura portuguesa se ressente lamentavelmente da inobservância da influência exercida pela Inquisição em toda a produção artística e intelectual lusitana, do século XVI ao século XVIII. É das coisas mais lamentáveis, na verdade, uma vez que em nenhum outro país europeu o tribunal agiu de maneira tão organizada e tão veemente, não apenas cerceando o desenvolvimento do pensamento, da literatura e das artes em 
geral: deve ser notada, também, a influência, sobre o pensamento popular, dos métodos, da ação e do policiamento constante do qual não escapavam nem as cidades nem a menor das vilas. Não é correto ignorar, como fatores de somenos na composição da mentalidade coletiva, o segredo, os falsos testemunhos, o cuidado nas atitudes que fatalmente poderiam ser tomadas como ambíguas. Posto que a Inquisição tenha se estabelecido, em Portugal, como secreto policiamento da fé, e como garantia do poder oligárquico, qualquer pessoa tornava-se um culpado em potencial. $\mathrm{O}$ perigo estava - literalmente, muitas vezes - no vizinho. Do estudo sobre a Inquisição portuguesa, portanto, não apenas podemos investigar as conseqüências para a arte, mas as conseqüências para o imaginário da grande maioria da população.

Antonio José Saraiva, num surpreendente estudo sobre o assunto, ${ }^{2}$ destaca, em certa altura, o questionamento que é um dos motores deste artigo: "como se refletia, nos escritores de situação cristã-nova, essa consciência particular de pária social?” A pergunta, ao que sei, nunca foi formulada, nem recebeu a atenção de nenhum estudioso da literatura e do pensamento português. No entanto, como fugir a ela?

A esta altura, o leitor deve estar se perguntando o que haveria entre a Inquisição e os elementos fragmentários da picaresca na prosa portuguesa. Este é o momento de se esclarecer o objetivo do trabalho, que é sustentar a idéia de que as tentativas fracassadas na elaboração de um corpus picaresco português, por um lado, se deve a uma apropriação da forma popular do gênero para fins de catequese; por outro lado, se deve a uma ideologia, imposta pelo medo, que sufocava os melhores talentos do tempo, não impedindo, todavia, mesmo uma disfarçada demonstração do espírito humanista, cético e problematizante. A proposição é de que, em Portugal, a novela picaresca espanhola exerceu sua influência de forma fragmentária: alguns autores foram fiéis à forma, mas mantiveram o caráter edificante da prosa tradicional; outros, se serviram pouco da forma, mas seus trabalhos são carregados de problematização da realidade. O que na picaresca espanhola estava indissociavelmente reunido, na picaresca portuguesa parece surgir apartado.

Já discutimos, acima, aquelas novelas que, por sua forma, são arroladas como picarescas, embora seu conteúdo seja obviamente clerical

${ }^{2}$ SARAIVA, 1984 , p. 89. 
e beato. Não parece errado dizer que a prosa portuguesa, desde o século XVI, apontava para uma tradição ideológica de manutenção do poder feudal, muito mais rigorosa do que foi em Espanha. A tendência para a heroicização acabou por minar a função denunciadora do anti-herói, e a crítica social (se há) é condicionada pelo paradigma religioso. O anti-herói da picaresca portuguesa não é um marginal como o espanhol: este último se apresenta como elemento marginal de uma sociedade por vezes grotesca em sua arrogância, e identifica-se com essa sociedade por sabêla acessível, quando há engenho. Em outras palavras, o pícaro espanhol elimina, através do pragmatismo de sua visão, o aparente abismo entre si e o fidalgo; reconhece que, na essência, são os mesmos. O português surge, também, como um elemento marginal. Marginal, porém, a um mundo corrompido; marginal, porque é um beato ao lado de lobos. Sua luta é para superar os vícios mundanos e a ambição, não para alcançar um posto que lhe garanta a sobrevivência "digna". O pícaro português se ampara no seio da ideologia, e sua crítica acaba por sintetizar, numa forma popular, toda a catequese que já havia sido representada pela literatura de molde erudito.

Outras obras, ainda que pouco picarescas em sua forma, deixam escapar através das máscaras do proveito exemplo ou da literatura de viagens, o sentido humano que as motivou. E, curiosamente, são obras escritas por cristãos-novos.

A Peregrinação, de Fernão Mendes Pinto, de 1614, é uma obra marcada por influências picarescas, demonstradas tanto pelo relato autobiográfico, quanto pelo cronotopo da viagem. Não basta, porém, para incluí-la nesta classificação. O humor dá lugar à sobriedade, de modo que se torna acentuada a ambigüidade entre o relato verdadeiro e a pura ficção. O fato de descrever terras estranhas é algo que dá, também, mais veracidade ao relato das andanças do personagem-narrador por terras da África e da Ásia. Mais do que o "verismo", mais do que o realismo das descrições e a verossimilhança das aventuras, está impressa na Peregrinação uma visão amargurada, refletida numa prosa às vezes ácida e violenta, sobre o imperialismo português no Oriente. Há uma preocupação perturbadora, do Autor, em denunciar a crueldade da expansão marítima, ao mesmo tempo em que narra suas desventuras pessoais e a tentativa de sobreviver em terras absolutamente estrangeiras, nas quais o apoio dos nativos lhe é tão duvidoso quanto o apoio dos compatriotas, retratados não como heróis camonianos, senão como aves 
de rapina. A insegurança impressa no livro de Fernão Mendes é algo que se deve à picaresca espanhola, e talvez mais especificamente ao pessimista Guzmán de Alfarache, pois dela bebe o pragmatismo que justifica o relato autobiográfico e a visão individual da própria vida.

No entanto, para que fosse picaresca, faltaria à Peregrinação elementos fundamentais, como a sátira e a vivacidade, que tornaram a picaresca espanhola mais pitoresca do que ácida, e até mesmo algo divertida. No entanto, não há espaço suficiente, no mundo de Fernão Lopes, para o humor, para aquele ridendo castigat mores tão caro à literatura popular desde a Idade Média. Fique assinalado, assim, que a Peregrinação é obra de um indivíduo desgarrado da ideologia católica; o narrador não é um aventureiro a narrar peripécias, mas um marinheiro "livre-pensador", apoiado em suas próprias noções de Bem e de Mal para medir o mundo ao seu redor.

Um outro exemplo de aproveitamento desse espírito cético da picaresca está nas Obras do diabinho da mão furada, cujo manuscrito anônimo é atribuído com propriedade a Antonio José da Silva, autor teatral de sucesso no século XVIII português, nascido no Rio de Janeiro em 1705 e executado num auto-de-fé, em Lisboa, em 1739. Neste livro, também conhecido como Ofradinho da mão furada, a forma picaresca se mistura à novela alegórica, e o enredo caminha de tal forma que muitos autores não hesitaram em considerá-la apenas mais uma novela "beata" de proveito e exemplo. O que se pode dizer é que poucos autores compreenderam seu sentido, como fizeram Bernard Emery, Vilma Areas e Maria Theresa Abelha Alves.

A história do soldado André Peralta, que, em tempos de Filipe II, se retira da milícia de Flandres, após vinte anos de serviço, é a história do homem sem parâmetros entre as noções de Bem e de Mal. É este soldado, pobre e maltrapilho, caminhando de volta à Lisboa natal, retornando de uma guerra perdida para o infiel protestante, a representação do fracasso das aspirações heróicas propagadas na Península. Seu encontro com o Diabinho da Mão Furada, figura demoníaca vestida de frade, é o pretexto para que se denuncie, sob um ponto de vista estritamente humano, o absurdo dos julgamentos num mundo em que todos, sem exceção, são pecadores.

Particularmente, as principais influências do texto, segundo estudiosos, são El diablo Cojuelo, de Guevara, Los sueños, de Quevedo, e uma novela de Cervantes, La ilustre fregona. No geral, o livro toma da 
picaresca uma série de procedimentos, incluindo a localização espacial, que permite ao autor fazer uma descrição pitoresca do interior de Portugal, e o tempo, que já não é marcado pelas mudanças de cena. Uma atenção especial, porém, deve ser dada à paródia.

A tradição popular, confirmada pela Inquisição, atribuía aos judeus uma série de blasfêmias que se baseavam na paródia do ritual católico. Por sua vez, o livro é uma espécie de paródia dessas crenças anti-semitas, na qual o Diabinho faz ver a Peralta que as culpas atribuídas aos judeus são comuns a todos os homens. O que se lê, na obra, são denúncias. É o Diabinho quem denuncia ao soldado a essência por trás da aparência: as beatas, à noite, se viram em bruxas que sugam o sangue dos recémnascidos. O mendigo à porta da igreja é um falso coxo. As noviças do convento usam de simpatias, astrologia, e necromancia, e a dama que serve na estalagem é uma reles prostituta.

Nas Obras do diabinho da mão furada está impressa uma dura e disfarçada crítica à hipocrisia. O Diabinho, enquanto denunciador da sociedade supersticiosa e desonesta, não faz mais que mostrar ao soldado a contradição existente entre aparência e essência. Entretanto, o tema central do livro já não é, como na picaresca, o da honra; temos, sim, o tema da fé. Para o soldado, a noção de verdade acaba por ser tão minada pelo Diabinho, seu desespero é tamanho, que a única saída é tornar-se frade, internando-se no Convento de Xabregas.

De referências à Inquisição o livro está repleto, e imprimo, com grifo próprio, aquela mais veemente, do momento em que o soldado procura recusar a panela de dinheiro que o Diabinho lhe oferece:

... A mim não enganam palavras. A verdadeira felicidade não consiste em ter tudo, senão em desejar nada; e sua Demonência bem sabe que neste mundo ofazer mal e ofazer bem tem igual perigo, porque nunca falta contradição a quem bem obra, nem quem é mau tem boa correspondência. Sempre observei o não teimar com rei nem superiores, nem com os ricos, e muito menos com os diabos; porque não há valor na natureza humana para porfiar muito, havendo de medrar pouco. ${ }^{3}$

Com essas duas obras, a Peregrinação e as Obras do Diabinho da Mão Furada, temos demonstrado o que faltou àquela picaresca rendida à edificação doutrinária: a visão problematizante. De todos os livros

3 SILVA, 1973, p. 25. 
discutidos aqui, nenhum, talvez, possa ser com certeza chamado picaresco. Faltou-lhes liberdade onde sobrou o medo, e a literatura portuguesa, depois do século XVIII, esperaria ainda muito tempo até ver surgir uma narrativa na qual a ficção problematizasse a realidade. E, se não foi possível, neste artigo, solucionar o problema da inexistência de uma tradição picaresca em Portugal, ao menos creio que se lançou uma possibilidade a mais de investigação. Penso que a ameaça da morte, e mesmo a ameaça representada pela vinculação da figura do escritor ao pensamento de um grupo religioso destinado à extinção, já bastariam para corromper a coragem de inovar a ficção, em Portugal. Por algum motivo, o pensamento erasmista fez frutos duradouros em Espanha. As razões dessa diferença, verificadas em países tão próximos, podem figurar como importante objeto de estudos posteriores. Por enquanto, penso que o trabalho de verificá-las chega a seu termo.

\section{Referências Bibliográficas}

PALMA-FERREIRA, João. Do picaro na literatura portuguesa. Lisboa: Instituto de Cultura e Língua Portuguesa, 1981.

SARAIVA, Antonio José. Inquisição e cristãos-novos. Lisboa: Europa-América, 1984.

SILVA, Antonio José da. Obras do Diabinho da Mão Furada. Lisboa : Arcádia, 1973.

SIMÕES, João Gaspar. História do romance português. Lisboa: Cor, 1967.

TRULLEMANS, Ulla. Huellas de la picaresca em Portugal. Madrid: Insula, 1968.

\section{Resumo}

Estudo sobre as novelas picarescas portuguesas dos séculos XVI, XVII e XVIII e a influência do Tribunal da Inquisição em sua feitura.

\section{Abstract}

A study on portuguese picaresque literature, during the XVI, XVII e XVIIIth centuries, and the influence of Inquisition on its making. 